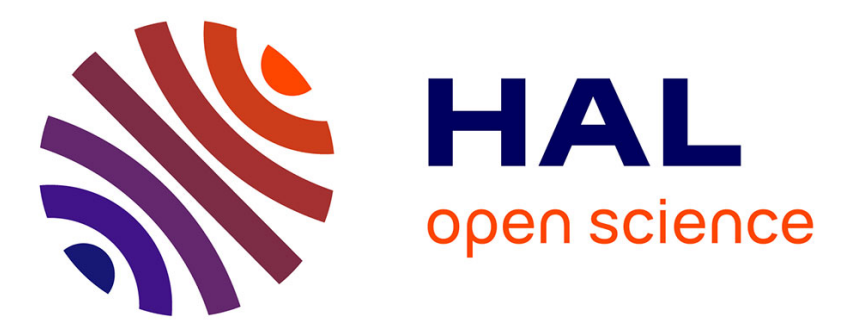

\title{
Integrated Laser Doppler Velocimeter made by Ion-Exchange in Glass Substrate
}

Pierre Lemaitre-Auger, Alain H. Cartellier, Pierre Benech, Isabelle

Schanen-Duport

\section{- To cite this version:}

Pierre Lemaitre-Auger, Alain H. Cartellier, Pierre Benech, Isabelle Schanen-Duport. Integrated Laser Doppler Velocimeter made by Ion-Exchange in Glass Substrate. Developments in Laser Techniques and Fluid Mechanics, Springer Berlin Heidelberg, pp.39-51, 1997, 10.1007/978-3-642-60911-4_4 . hal02388175

\section{HAL Id: hal-02388175 \\ https://hal.univ-grenoble-alpes.fr/hal-02388175}

Submitted on 2 Mar 2021

HAL is a multi-disciplinary open access archive for the deposit and dissemination of scientific research documents, whether they are published or not. The documents may come from teaching and research institutions in France or abroad, or from public or private research centers.
L'archive ouverte pluridisciplinaire HAL, est destinée au dépôt et à la diffusion de documents scientifiques de niveau recherche, publiés ou non, émanant des établissements d'enseignement et de recherche français ou étrangers, des laboratoires publics ou privés.

\section{(c)(1)}

Distributed under a Creative Commons Attribution| 4.0 International License 


\title{
Integrated Laser Doppler Velocimeter made by Ion-Exchange in Glass Substrate
}

\author{
P.L.-Auger' ${ }^{1}$ A. Cartellier ${ }^{2}$, P. Benech' and I. Schanen Duport ${ }^{1}$ \\ 1 LEMO, UMR 5530 INPG-UJF-CNRS, 23 Avenue des Martyrs, BP 257, 38016 \\ GRENOBLE CEDEX, France \\ ${ }^{2}$ LEGI, UJF-CNRS-INPG, BP 53 X, 38041 GRENOBLE CEDEX, France
}

\begin{abstract}
A fully integrated laser Doppler velocimeter made by ion-exchange in a glass substrate is presented. Thanks to the integration of both the emission and reception systems, no optical adjustment are required. Beside, when flush mounted on a wall, this LDV does not collect the unwanted reflected light caused by the proximity of that wall. It is thus well suited for velocity measurements in boundary layers. In this paper, the fabrication technique is thoroughly described and some qualifications are commented. In the prospect of wall shear stress measurements, it is also shown that, by optimizing the waveguiding structure, highly localized velocity measurements are accessible.
\end{abstract}

Keywords. Integrated Velocimeter, LDV, LDA, Integrated Optics, IonExchange

\section{Introduction}

Measurements of velocity gradients in the viscous sublayer is not an easy task. Among the non intrusive possible techniques, laser Doppler anemometry is probably the best one. ${ }^{[1-3]}$ Such apparatus made in classical volume optic are found in research laboratories and industries despite their elevated cost. For such systems, both the emission and the reception system are located outside the fluid flow and requires the presence of transparent walls. Their spatial resolution depends mainly on the size of the measuring volume formed by the intersection of the two lasers beams. The smallest ones are comprise between $30 \times 20 \times 20 \mu \mathrm{m}^{3}$ and $200 \times 200 \times 300 \mu \mathrm{m}^{3}{ }^{[4-7]}$ and requires rather complex lenses system which is relatively big. The shortest distance between the measuring volume and the channel wall doesn't go under 100 to $200 \mu \mathrm{m}^{[8-10]}$ One of the reason for this is that diffused light is reflected from the wall and degrades the optical signals received. Also, if the measuring volume touches the wall, then unwanted reflection of the volume itself will also cause a degradation of the signals. ${ }^{[11-12]}$

Partially integrated velocimeter were also developed. ${ }^{[13]}$ In that case, the emission system was introduced through the channel wall but the reception system was still exterior to the fluid flow. Direct velocity gradient were measured with 
such a partially integrated captor. ${ }^{[13]}$ The fringe spacing varied linearly with the distance. However, rather long optical adjustments were required and the uncertainty was quite large $( \pm 50 \%)$.

In the present paper, we propose a first prototype of a fully integrated velocimeter, i.e. including the emission and the reception, able to be introduced inside a channel wall. Reception is done on the same side as the emission. For this velocimeter, no adjustments of any kind by an operator are required. The final aim of the project is to produce a velocimeter with a very high spatial and temporal resolution. The measuring volume will be located inside the viscous sublayer $\left(\mathrm{y}^{+} \leq 6\right)$. So indirect measurements of the velocity gradient and the skin friction by the same way could be done.

The fabrication of the velocimeter is first presented. Afterwards, a description of it is given. Measurements obtained with an optical fiber, as the reception element of the optical signals, are then presented and discussed. Finally, possibilities offered by a new configuration of interferometer are discussed.

\section{Fabrication}

The main part of the velocimeter is the system producing the fringes. It is realized by integrated optic techniques on a glass substrate. The choice of that substrate was governed by the fact that glass is well suited to realize passive components. ${ }^{[14]}$ It is indeed a cheap materiel with good optical properties. Also, the technique of ion-exchange, the most widely used technique to produce waveguides on glass, is well controlled. ${ }^{[14-16]}$

To realize the present velocimeter prototype, Mentzel soda-lime glass is utilized. It is first clean in a tensio-actif industrial soap solution (Decon soap) that takes out organic as well as inorganic contaminants. Then, a layer of approximately $150 \mathrm{~nm}$ of aluminum is evaporated on it. Afterwards, standard photolithography process employed in the fabrication of integrated circuits is used. Positive photoresist is spinned over the aluminum $(0,5 \mu \mathrm{m}$ thick). The guiding structure is reproduced from the photolithographic mask to the resist by exposition to U. V. light, as it is shown on figure 1. Exposed resist will be dissolved in a developer solution, contrarily to the unexposed one. Aluminum can then be locally chemically attacked with an acid solution. After that, all of the remaining photoresist is removed with acetone. As the final result, the guiding structure is present on the aluminum layer.

The glass plate with his aluminum coating is immersed in a pure molten salt of potassium nitrate $\left(\mathrm{KNO}^{3}\right)$. An exchange between the potassium ions present in the salt and the sodium ions contained in the glass takes place over specific regions where there is no aluminum present, see figure 1, the latter blocking the diffusion of ions. A specific waveguiding pattern is thus created in the glass by this way. Indeed, due to the difference between the size of the sodium and the potassium ions, local constraints are created in the glass that give rise to an increase of the refractive index. 

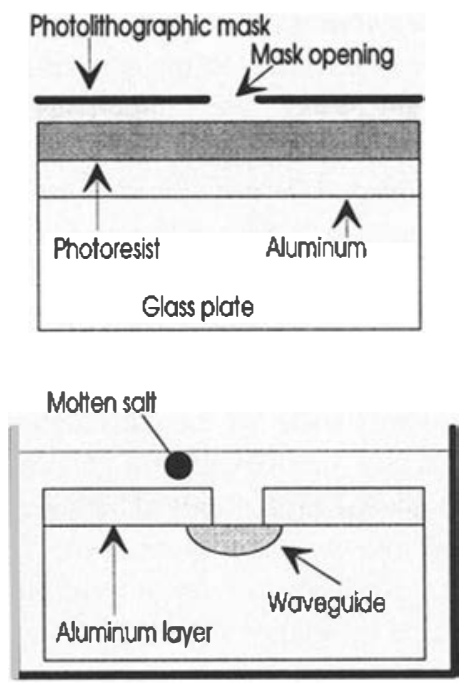

Fig. 1. The photolitographic process. Top) U. V. exposition. Bottom) Ion-exchange step

For the sample fabricated, the exchange took place for 4 hours at a temperature of $350^{\circ} \mathrm{C}$. In those conditions, the maximum index change is 0.11 .

Finally, the aluminum layer is removed and both edges of the glass plate , corresponding to the entrance and exit sides of the light trajectory, are mechanically polished at a precision of $0.1 \mu \mathrm{m}$.

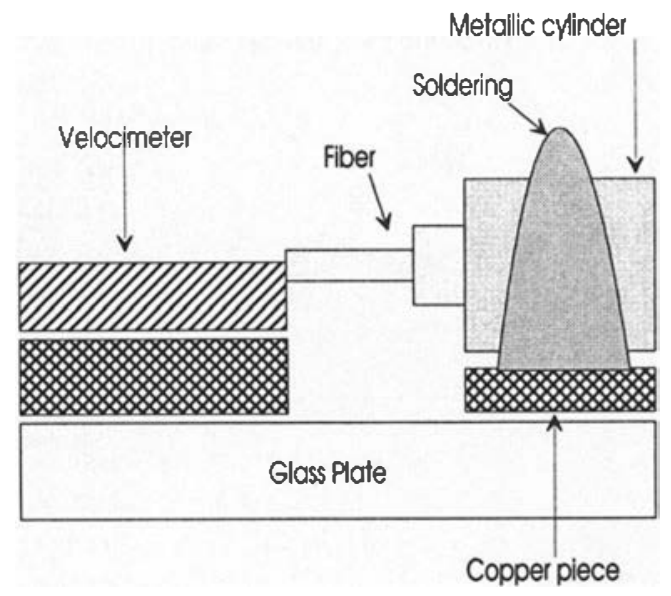

Fig. 2. Schematic representation of the connection between the optical fiber and the glass sample 
A singlemode optical fiber connected to a pigtail laser diode is glued inside a small metal cylinder which is attached to the sample by soldering it to a small copper piece glued on a support plate, like can be seen in figure 2 . The procedure is relatively easy to do but rather long. Nevertheless, the attachment is mechanically very solid, it resists to water and to humidity and it is quite stable in time. No coupling power change could be observed for a 12 months old sample.

\section{Description of the Integrated Velocimeter}

The integrated guiding structure used for the emission of the fringes is shown on figure 3. The first part of it is a singlemode straight waveguide which is coupled to the optical fiber of the pigtail laser diode which wavelength is $832 \mathrm{~nm}$. The guided light is then divided into two equal parts in the $\mathrm{Y}$-junction. The latter plays the role of a beam splitter. Each arm of the interferometer that follows has the same length and is terminated by a taper structure. ${ }^{[17]}$ the purpose of the latter is to excite only the fundamental mode of a multimode waveguide of $40 \mu \mathrm{m}$ width (this width is the one of the photolitographic mask opening). The distribution of light intensity is almost Gaussian. The size of a single waveguide, $2 \mu \mathrm{m}$, is small and the beam produced by such an optical waveguide would strongly diverge in free space while the beam issued from the fundamental mode of a $40 \mu \mathrm{m}$ waveguide will act like a quasi-collimated beam. The divergence of the latter is on order of $1.5^{\circ}$.

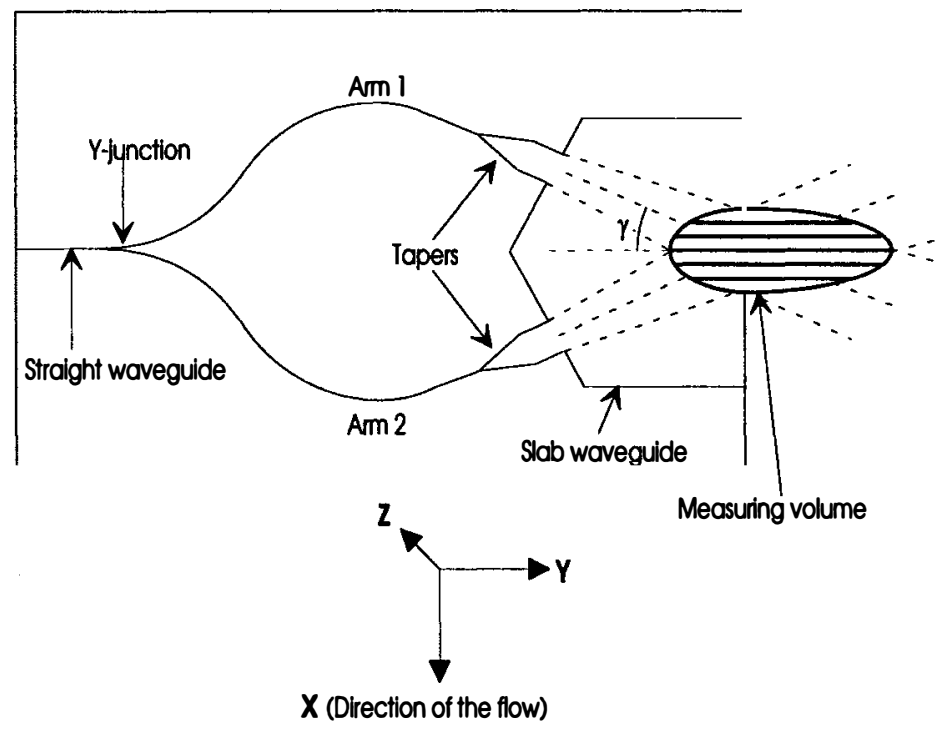

Fig. 3. Schematic representation of the integrated emission system 
The output beams of the two tapers will then travel in a slab waveguide, where light is confined in one dimension only, and will produce the interference pattern. ${ }^{[18]}$ Half of the latter exist inside the glass plate while the other half is outside the exterior medium. That does not have to be the case : the interference pattern could completely be outside the glass plate. Still, the present waveguiding geometry imposes that fact. In both mediums, it is easy to demonstrate that the fringe spacing $(\Delta x)$ is given by :

$$
\Delta x=\frac{\lambda_{0}}{2 N_{e f f} \sin \gamma},
$$

where $\lambda_{0}$ is the wavelength in free space, $N_{\text {eff }}$ is the effective index of the slab waveguide and $\gamma$ is the half angle between the two beams (see fig. 3). It is worth noting that the fringe spacing is independent of the refractive index of the exterior fluid. The position of the measuring volume (in the case where it would entirely be outside the glass plate) and its dimensions do depend however upon the fluid index. Ulrich and Martin ${ }^{[19]}$ have indeed demonstrated that light, when guided in a slab waveguide, follows Snell law of refraction with the effective index instead of the refractive index of the bulk materiel.

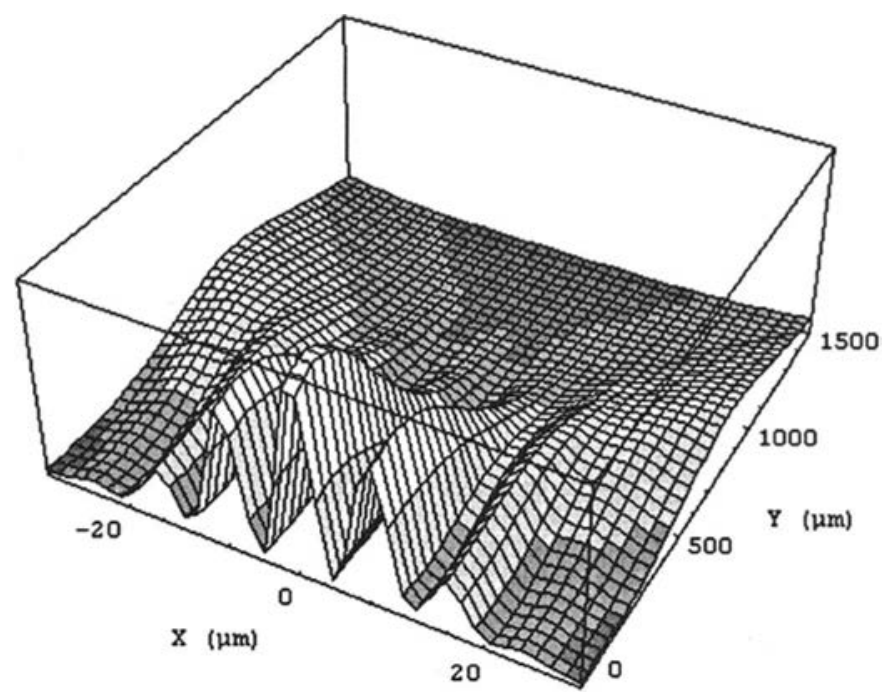

Fig. 4. Computed interference fringe of the measuring volume at $z=0$ in water

For the present prototype, the angle between the two beams inside the glass is $1.8^{\circ}$, the fringe spacing $8.77 \mu \mathrm{m}$. The width of the output beam at $1 / \mathrm{e}^{2}$ of the 
intensity produced by the taper is $36 \mu \mathrm{m}$. In those conditions, the size of the measuring volume in water (half of the whole interference region) is approximately $60 \mu \mathrm{m} \times 1000 \mu \mathrm{m} \times 50 \mu \mathrm{m}$, as shown in the calculation of figure 4 . The present configuration is therefore not adapted for measurements in the viscous sublayer. Nevertheless, it demonstrates the feasibility of such a velocimeter.

An image of the fringe pattern observed with a digital camera on the edge of the glass is given in figure 5 as well as the corresponding intensity profiler. The contrast ratio being only 0.9 is explained by the fact that the middle of the fringe pattern is not exactly located on the edge of the glass. The geometry of the tapers causes the envelope of the fringes (fig. 5) not to be a Gaussian type. Other taper produces Gaussian type envelope, like shown on fig. 6, but due to the small angle available at the present time between the beams, the number of fringes is not sufficient enough for a LDV. This will be corrected in future configurations.
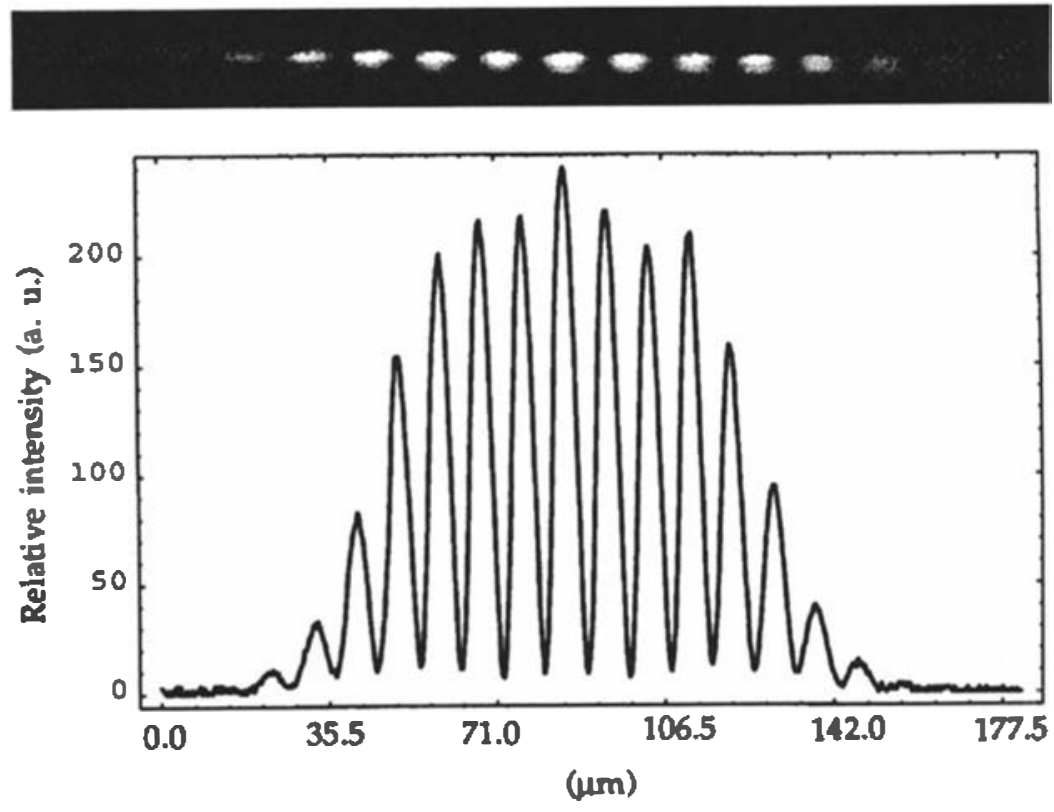

Fig. 5. Top) Image of the fringe pattern on the edge of the glass. Bottom) Corresponding intensity

The total optical output power of the sample for an input power of $30 \mathrm{~mW}$ is $0,95 \mathrm{~mW}$, corresponding to $15 \mathrm{~dB}$ optical loss in the sample. The propagation losses are estimated to $1 \mathrm{~dB} / \mathrm{cm}$, so the major part of those losses $(11 \mathrm{~dB})$ comes from the connection between the optical fiber and the sample. Great care must 
then be taken when connecting the fiber to the sample. Total losses on the order of $8 \mathrm{~dB}$ can reasonably be expected.

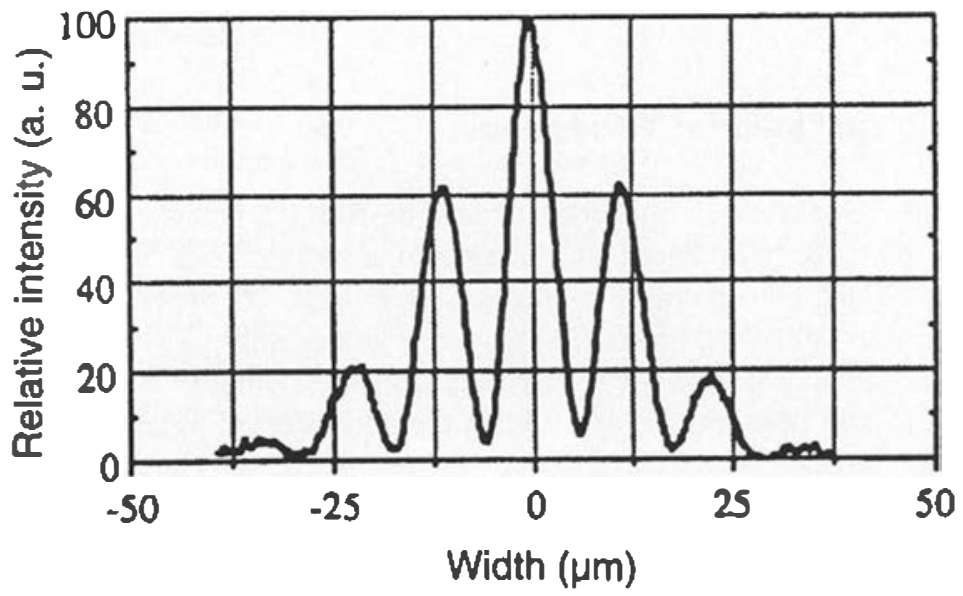

Fig. 6. Fringe pattern produced with a different taper and having a Gaussian envelope

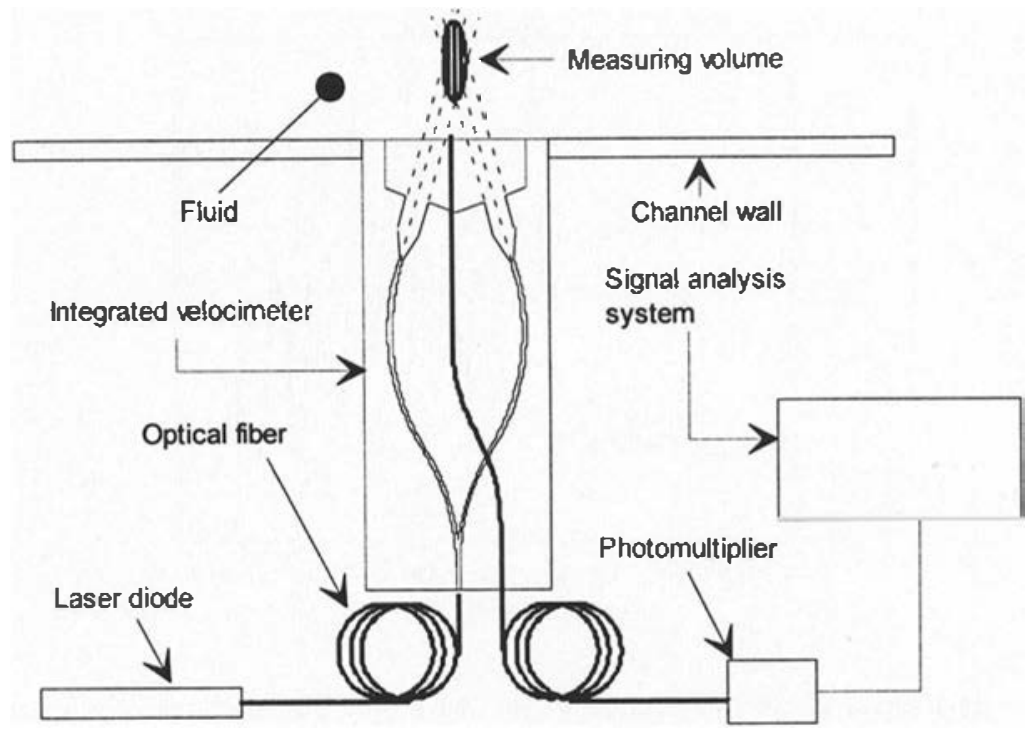

Fig. 7. Scheme of the complete integrated velocimeter

Finally, an optical fiber, that can easily be glued on the glass plate, collects the light scattered by particles passing in the measuring volume and transmits it to a 
photomultiplier. The scheme of the complete integrated velocimeter is given in fig. 7. Because the laser diode and the photomultiplier can both be several meters apart from the head of the velocimeter, measurements can be done in places of difficult access.

\section{First Experimental Validations}

To test the velocimeter, a metallic cylinder of $500 \mu \mathrm{m}$ diameter is used as the diffusing particle. It is placed on the side of a rotating disk of $4.3 \pm 0.2 \mathrm{~cm}$ diameter, making two complete revolutions per minute. The speed of the diffusing element is thus $0,90 \pm 0.04 \mathrm{~cm} / \mathrm{s}$. The extremity of the emitting system was placed at a distance of approximately $0.5 \mathrm{~mm}$ away from the cylinder.

First, a plastic fiber was used to collect the retrodiffused light. An example of the signals obtained on an oscilloscope is given in fig. 8. A low-pass filter was used to lower the noise produced by the amplification circuit following the photomultiplier. The measured Doppler frequencies ranging from 1.02 to 1.08 $\mathrm{kHz}$ correspond to velocities comprise between 0.894 and $0.947 \mathrm{~cm} / \mathrm{s}$, which are comparable to the one calculated above

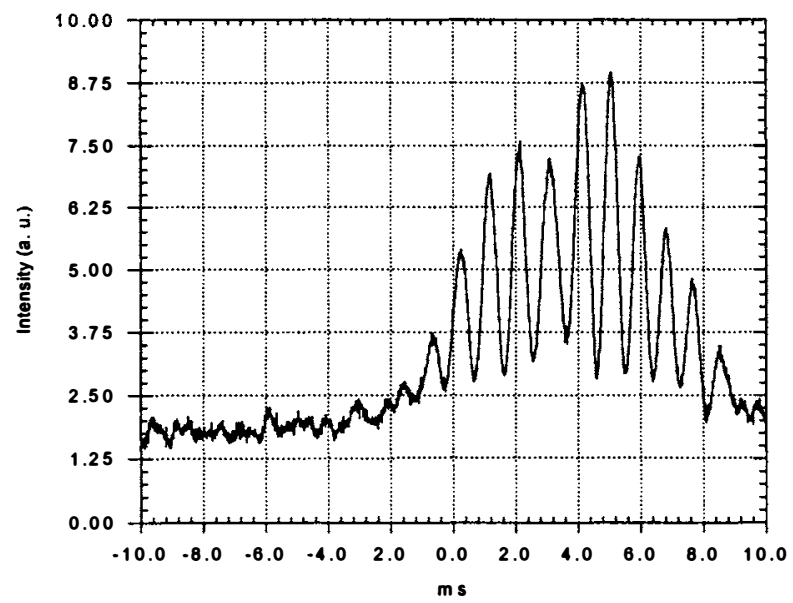

Fig. 8. Example of Doppler burst obtained with the plastic fiber as the reception element. Longitudinal distance is $24 \mathrm{~mm}$. A low-pass filter $(2.5 \mathrm{kHz})$ was used

The reception fiber was allowed to move freely in regard to the glass plate. Study of the Doppler signal as a function of the position of the fiber was done that 
way. The longitudinal distance between the fiber extremity and the glass edge was varied. For each position, the signal visibility $(\eta)$, defined as :

$$
\eta=\frac{I_{\max }-I_{\min }}{I_{\max }+I_{\min }}
$$

where $I_{\max }$ and $I_{\min }$ are respectively the maximum and minimum intensities of the signal measured, is calculated. Figure 9 shows the results of that study. It can be seen from the graph that a distance of $24 \mathrm{~mm}$ gives the maximum ratio, 0.73 . For greater distances, it becomes difficult to discern the signal from the noise. Also, one has to keep in mind that the center of the measuring volume is located very near the side of the glass plate, so a ratio of 1 is impossible to get in those conditions. The conclusion of that first study is that plastic fiber is inadequate for measures in the subviscous layer because its extremity cannot be placed next to the edge of the glass. This is essential if the velocimeter is to be placed inside the wall of a channel. Nevertheless, it should be considered in the case where someone would like the measuring volume to be at a distance from the wall in the order of 1 or $2 \mathrm{~cm}$.

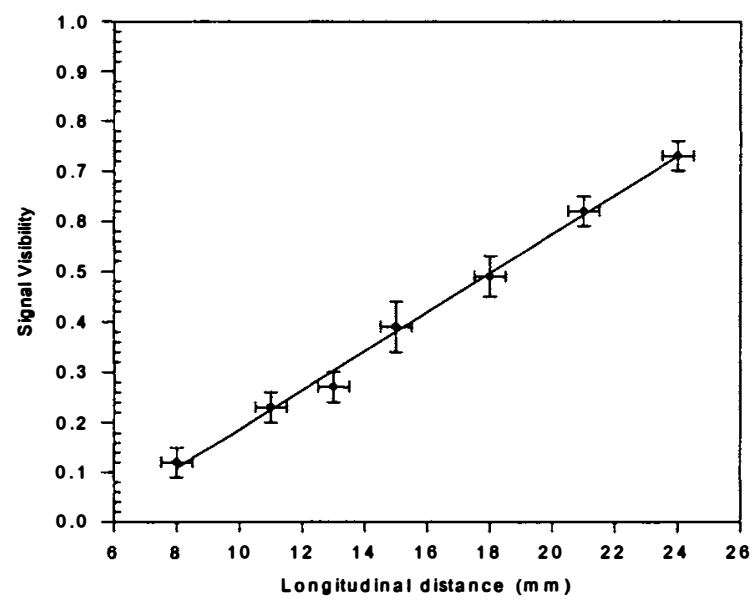

Fig. 9. Visibility as a function of the longitudinal distance between the fiber and the glass

The same study was done but with a multimode silica fiber $(100 / 140 \mu \mathrm{m})$ this time. In that case, Doppler frequencies could be observed for a distance varying from 0 to at least $4 \mathrm{~mm}$ between the fiber extremity and the glass side. Example of filtered and non filtered signals are given in figure 10. The lateral position of the fiber is however critical for a null longitudinal distance. It has to be placed within $\pm 100 \mu \mathrm{m}$ from the symmetry axis of the integrated guiding structure. Signal 
merging from a measuring volume located between 0 and $500 \mu \mathrm{m}$ of the glass side can be collected with that multimode fiber glued on the glass plate.
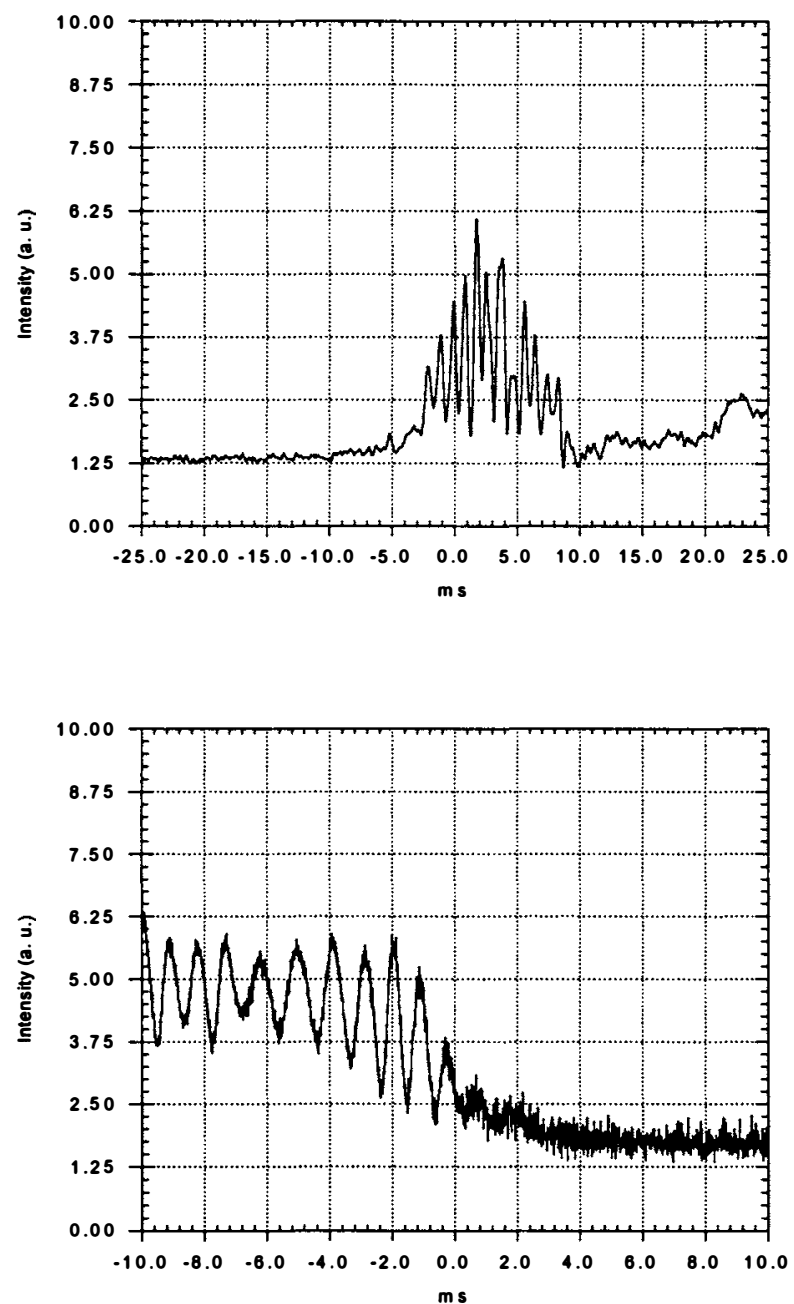

Fig. 10. Example of signals obtained with the silica multimode fiber. Top) low-pass filter $(2.5 \mathrm{kHz})$ used. Bottom) No electric filter used

\section{New Generation of Prototype}

The measuring volume of our first prototype is however too large for accurate velocity measurements in the viscous sublayer. The actual configuration but with 
a different geometry could produce measuring volumes of $50 \times 65 \times 10 \mu \mathrm{m}^{3}$ in water (75 $\times 50 \times 15 \mu \mathrm{m}^{3}$ in air) with a fringe spacing of $0.5 \mu \mathrm{m}$. The distance from the glass side is $100 \mu \mathrm{m}$. This seems to be the limit of the taper configuration.

To further improve the spatial resolution, a new design of the interferometer has been imagined using a convergent structure. Optical simulations show that it should provide a probe volume of $15 \times 20 \times 40 \mu \mathrm{m}^{3}$ in water, located at a distance ranging between 0 up to $500 \mu \mathrm{m}$ from the glass side. The fringe spacing is 0.5 $\mu \mathrm{m}$. The probe volume extend along the direction normal to the wall is $20 \mu \mathrm{m}$. This design is well adapted to wall shear stress measurements. Some of these new prototypes have been manufactured and are currently under test in terms of optical performances. In the near future, their performance with respect to wall shear stress measurements will be checked in various well controlled flow conditions, both in air and water flows.

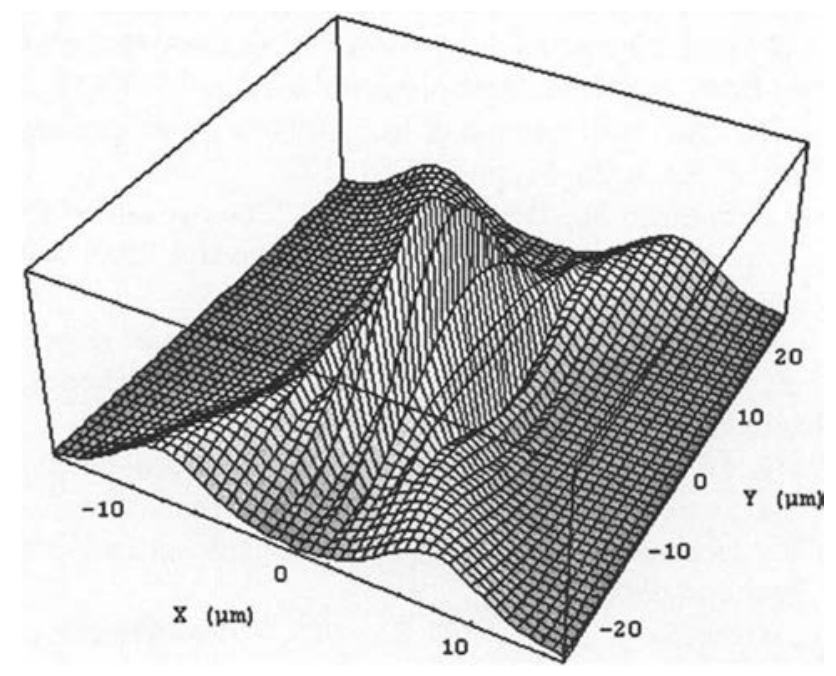

Fig. 11. Example of computed fringe pattern of the measuring volume of the new prototype at $\mathrm{z}=0$ in water

\section{Conclusion}

A first prototype of an integrated laser Doppler velocimeter has been presented. Its emission system has been made by integrated optics techniques on a glass substrate. Using a reception consisting of either a multimode silica fiber or a plastic fiber, Doppler bursts from retrodiffused light and with good visibility have 
been . recorded. The feasibility of this technique has thus been demonstrated, indicating that the combination of an integrated optical interferometer and a multimode optical fiber is an easy and efficient way to produce cheap velocimeters free of optical adjustments. Future words will be devoted to the qualification of wall shear stress measurements using a new generation of prototypes allowing a much better spatial resolution.

\section{Acknowledgments}

The first author would like to thank the FCAR organization of the Quebec government for a doctoral research grant. Authors are grateful to PIR Ultimatech for financial support under grant $24 \mathrm{~N}$-II.4.1.

\section{References}

[1] Hanratty TH.J., Campbell J.A., 1983, "Chapter 11 : Measurement of wall shear stress", in Fluid Mechanics Measurements, Golstein R.J. Ed., Hemisphere Publishing Corp., distributed by Springer-Verlag, pp. 559-611.

${ }^{[2]}$ Saetran L.R., 1987, "Comparison of five methods for determination of the wall shear stress, AIAA J., 25, 11, pp. 1524-1527.

[3] Gasser D., Thomann H., Dengel P., 1993, "Comparison of four methods to measure wall shear stress in a turbulent boundary layer with separation", Experiments in Fluids, 15, pp. 27-32.

${ }^{[4]}$ Martin S.R., Bates C.J., 1992, "Small-probe-volume laser Doppler anemometry measurement of turbulent flow near the wall of a rib-roughened channel" Flow Meas. Instrum. Vol. 3, No. 2, pp. 81-88.

${ }^{[5]}$ Leprince F., Riethmuller M.L., 1986, "LDV Measurements in a viscous sublayer : determination of skin friction", Laser Techniques and Applications in Fluids Mechanics - Proceedings of the 3rd International Symposium, Lisbon, Portugal, paper 1-6.

${ }^{[6]}$ Aizu Y., Ushizaka T., Asakura T., 1985, "Measurement of the Velocity Gradient Using a Laser Doppler Phenomenon", Appl. Phys. B 36, pp. 155-161.

${ }^{[7]}$ Keveloh C., Staude W., 1983, "Determination of velocity gradients with scattered light cross-correlation measurements" Applied Optics, Vol. 22, No 2, pp. 333-338.

[8] Wernet M.P., Edwards R.V., 1986, "Implementation of a new time of flight laser anemometer", Applied Optics, Vol. 25, No 5, pp. 644-648.

[9] Dybbs A., Edwards R.V., 1987, "Refractive index matching for difficult situations", 2nd Int. Conf. Laser Anemometry - Advances and Applications, Glascow, UK, BHRA, Cranfield, paper 1-22.

${ }^{[10]}$ Durst F., Keck T., Kleine R., 1985, "Turbulence quantities and Reynolds stress in pipe flow of polymer solutions", 1st Int. Conf. Laser Anemometry Advances and Applications, Manchester, UK, BHRA, Cranfield, paper 35-52. 
${ }^{[11]}$ Mishina H., Vlachos N.S., Whitelaw J.H., 1979, "Effect of wall scattering on SNR in laser Doppler anemometry", Applied Optics, Vol. 18, No 14, pp. 24802485.

${ }^{[12]}$ Cline C., Deutsh S., 1993, "On elevated RMS levels in wall-bounded turbulent flows when measured by laser Doppler velocimetry", Experiments in Fluids, Vol. 15, pp. 130-132.

${ }^{[13]}$ Petrik S., Naqwi A.A., Durst F., 1992, "Fiber optic dual-cylindrical wave sensor for measurement of flow velocity gradients", 2nd French-German workshop on Optical Measurement Techniques - Fibers Optics and Instrumentation, 13-14 October, St. Etienne, France.

${ }^{[14]}$ Johansson J., Djanta G., and Coutaz J.-L., 1992, "Optical waveguide fabricated by ion exchange in high-index commercial glasses", Applied Optics, Vol. 31, No 15, pp. 2796-2799.

${ }^{[15]}$ Ramaswamy R.V. and Srivastava R., 1988, "Ion-exchanged glass waveguides : a review", Journal of Lightwave technology, Vol. 6, No 6, pp. 984-1001.

${ }^{[16]}$ Findakly T., 1985, "Glass waveguides by ion exchange : a review", Optical engineering, Vol. 24, No 2, pp. 244-250.

${ }^{[17]}$ Duport I., Benech P., Kahlil D., Rimet R., 1994, Study of linear tapered waveguides made by ion exchange on glass", J. of Physics, D : Applied Physics, 25, pp. 913-918.

${ }^{[18]}$ Schanen Duport I., Benech P., Rimet R., 1984, "New integrated-optics interferometer in planar technology", Applied Optics, Vol. 33, No 35, pp. 5954-5958.

${ }^{[19]}$ Ulrich R. and Martin R.J., 1971, "Geometrical optics in thin film light guides", Applied Optics, Vol. 10, pp. 2077-2085. 